\title{
Relationship between maximal fat oxidation and oxygen uptake: comparison between type 2 diabetes patients and healthy sedentary subjects
}

\author{
Angelo Cataldo, Giuseppe Russo, Dario Cerasola, Danila Di Majo, Marco Giammanco, \\ Marcello Traina
}

Department of Law, Society and Sports Studies, University of Palermo, Italy

\begin{abstract}
The contribution of fat oxidation to energy production during exercise is influenced by intensity of exercise. The aim of this study was to assess the relationship between the highest value of fat oxidation rate $\left(\mathrm{FAT}_{\max }\right)$ and the oxygen uptake $\left(\mathrm{VO}_{2}\right)$ in sedentary type 2 diabetes (T2D) patients $v s$ healthy sedentary subjects. Sedentary T2D patients and healthy sedentary subjects were evaluated to a graded exercise test, and oxygen uptake and fat oxidation rate were detected. Data show that in T2D patients fat oxidation rate is not impaired and the positive linear correlation between $\mathrm{FAT}_{\max }$ and both $\mathrm{VO}_{2}$ and $\mathrm{VO}_{2 \max }$ suggests that even in T2D patients the muscle oxidative capacity might increase in response to aerobic training.
\end{abstract}

\section{Introduction}

Carbohydrate and fatty acids are the dominant fuels oxidized for energy production during exercise. Their contribution is influenced by intensity of exercise, ${ }^{1}$ with a progressive increase in the relative contribution of carbohydrate oxidation to energy expenditure, whereas the absolute rate of fat oxidation increases from low to moderate intensities of exercise and declines as exercise becomes more intense. ${ }^{2,3}$ In patients with type 2 diabetes (T2D) the altered metabolism and the lower capacity to sustain efforts ${ }^{4}$ changed the choice and regulation of energy substrates for oxidation. ${ }^{5}$

Purpose of this study was to assess the relationship between the

Correspondence: Department of Law, Society and Sports Studies, University of Palermo, via Maqueda 172, 90134 Palermo, Italy.

Tel. +39.091 .23860809 - Fax: +39.091 .23892216 .

E-mail: angelo.cataldo@unipa.it

Key words: metabolism, fat oxidation rate, oxygen uptake, exercise, diabetes.

CCopyright A. Cataldo et al., 2014

Licensee PAGEPress, Italy

Journal of Biological Research 2014; 87:2136

doi:10.4081/jbr.2014.2136

This article is distributed under the terms of the Creative Commons Attribution Noncommercial License (by-nc 3.0) which permits any noncommercial use, distribution, and reproduction in any medium, provided the original author(s) and source are credited. highest value of fat oxidation rate $\left(\mathrm{FAT}_{\max }\right)$ and the oxygen uptake $\left(\mathrm{VO}_{2}\right)$ in sedentary T2D patients in comparison with healthy sedentary subjects.

\section{Materials and Methods}

Fifteen sedentary T2D patients ( 9 males, 6 females), mean age 58 (range 39-65) and fifteen healthy sedentary subjects (8 males, 7 females), mean age 53 (range 37-71), were studied. The physical and physiological characteristics of subjetcs are shown in Table 1.

All T2D patients were being treated with diet and antiglycemic agents. Significant cardiovascular disease was excluded in all subjects by an instrumental examination. Each subject gave his written informed consent after explanation of the experimental procedures. The exercise testing started in the laboratory at 8.00 a.m. after an overnight fast. All subjects performed a graded exercise test to exhaustion on treadmill, using modified Bruce protocol. Oxygen uptake $\left(\mathrm{VO}_{2}\right)$ and carbon dioxide $\left(\mathrm{VCO}_{2}\right)$ were recorded with a breath-by-breath measurement system (Cosmed Quark CPET; Cosmed Srl, Rome, Italy) and maximum fat oxidation rate $\left(\mathrm{FAT}_{\max }\right)$ was determined using indirect calorimetry, with the assumption that urinary nitrogen excretion rate was negligible. Peak $\mathrm{VO}_{2}$ was recorded as the highest consecutive $30 \mathrm{~s}$ average value during the last minute of exercise or early recovery. Substrate oxidation rates were then plotted as a function of exercise intensity, expressed as percentage of maximal oxygen uptake $\left(\mathrm{VO}_{2 \max }\right)$. From each fat oxidation curve, the peak rate of fat oxidation measured over the entire range of exercise intensities $\left(\mathrm{FAT}_{\max }\right.$ and the exercise intensity at which the fat oxidation rate was maximal, in absolute and percentage of maximal oxygen uptake $\left(\mathrm{VO}_{2} ; \% \mathrm{VO}_{2 \max }\right)$, were identified. All responses were monitored throughout rest, exercise and recovery, and grafically displayed. Data are shown as means \pm standard deviation. GraphPad InStat sofware was used to analyze differences between sets of data and for the linear regression analysis.

\section{Results}

The average of body mass index (BMI) was $28.7 \pm 1.07$ for T2D patients and $26.6 \pm 1.3$ for healthy subjects. The average $\mathrm{VO}_{2 \max }$ was $22.29 \pm 1.06$ and $28.63 \pm 2.03 \mathrm{~mL} / \mathrm{kg} / \mathrm{min}$ for T2D patients and healthy subjects, respectively $(\mathrm{P}<0.01)$. In $\mathrm{T} 2 \mathrm{D}$ patients, absolute fat oxidation rate reached a maximum of $6.71 \pm 0.46 \mathrm{mg} / \mathrm{kg} / \mathrm{min}$ at $\mathrm{VO}_{2}$ of $15.41 \pm 0.68$ $\mathrm{mL} / \mathrm{kg} / \mathrm{min}\left(70 \pm 1.27 \%\right.$ of $\left.\mathrm{VO}_{2 \max }\right)$, while in healthy subjects $7.19 \pm 0.77$ $\mathrm{mg} / \mathrm{kg} / \mathrm{min}$ at $\mathrm{VO}_{2}$ of $18.23 \pm 1.28 \mathrm{~mL} / \mathrm{kg} / \mathrm{min}\left(64 \pm 2.61 \%\right.$ of $\left.\mathrm{VO}_{2 \max }\right)$. A positive linear correlation $(\mathrm{r}=0.85 ; \mathrm{P}=0.0001)$ between $\mathrm{FAT}_{\max }$ and $\mathrm{VO}_{2}$ in both groups has been found (Figure 1). 
Table 1. Physical and physiological characteristics of subjects.

$\begin{array}{ccc}\text { Characteristics } & \text { T2D } & \text { Healthy P } \\ \text { patients } & \text { subjects }\end{array}$

\begin{tabular}{lccc}
$\mathrm{n}$ & 15 & 15 & \\
Age (years) & $58 \pm 1.78$ & $53 \pm 2.04$ & \\
\hline Height $(\mathrm{cm})$ & $168 \pm 2.32$ & $167 \pm 2.58$ & \\
Weigth $(\mathrm{kg})$ & $81 \pm 3.20$ & $75 \pm 4.69$ & \\
\hline $\mathrm{BMI}$ & $28.7 \pm 1.07$ & $26.6 \pm 1.3$ & \\
$\mathrm{VO}_{2 \max }(\mathrm{mL} / \mathrm{kg} / \mathrm{min})$ & $22.29 \pm 1.06$ & $28.63 \pm 2.03$ & $* *$ \\
\hline $\mathrm{FAT}_{\max }(\mathrm{mL} / \mathrm{kg} / \mathrm{min})$ & $6.71 \pm 0.46$ & $7.19 \pm 0.77$ & \\
$\mathrm{VO}_{2}$ at $\mathrm{FAT}_{\max }(\mathrm{mL} / \mathrm{kg} / \mathrm{min})$ & $15.41 \pm 0.68$ & $18.23 \pm 1.28$ & $*$ \\
\hline $\mathrm{VO}_{2 \max }$ at $\mathrm{FAT}$ & \\
\hline
\end{tabular}

T2D, type 2 diabetes; BMI, body mass index. Data are expressed as means \pm standard deviation. ${ }^{*} * \mathrm{P}<0.05$ for difference between healthy and T2D subjects; ${ }^{*} \mathrm{P}<0.01$ for differences between healthy and T2D subjects.
Also, positive linear correlation between $\mathrm{FAT}_{\max }$ and $\mathrm{VO}_{2 \max }$ in both type 2 diabetes $(\mathrm{r}=0.76 ; \mathrm{P}=0.001)$ and healthy subjects $(\mathrm{r}=0.73$; $\mathrm{P}=0.002$ ) has been found (Figure 2).

\section{Discussion}

Exercise intensity looks very important in determining substrate utilization. ${ }^{6}$ In normal subjects, on increasing exercise intensity from low to moderate, absolute lipid oxidation keeps increasing but, on increasing further, fat oxidation rates decrease markedly. Subjects with T2D could have an abnormal pattern of substrate recruitment for oxidation during exercise. Our data, as found in literature, ${ }^{7}$ indicate that in T2D patients fat oxidation rate is not impaired. $\mathrm{VO}_{2 \max }$, index of exercise capacity, was significantly lower in T2D patients so that, in T2D compared to healthy subjects, we found a maximal fat rate oxidation at higher exercise inten-
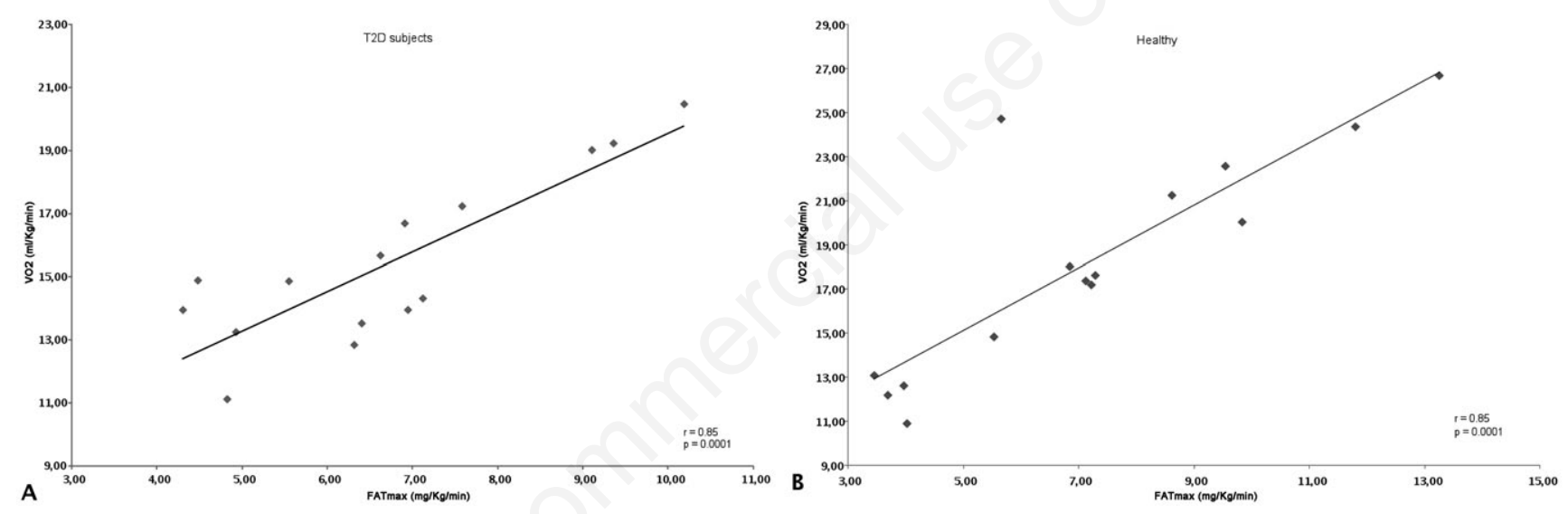

Figure 1. Correlations between $\mathrm{FAT}_{\max }$ and $\mathrm{VO}_{2}$ in type 2 diabetes $(\mathrm{A})$ and healthy $(\mathrm{B})$ subjects.
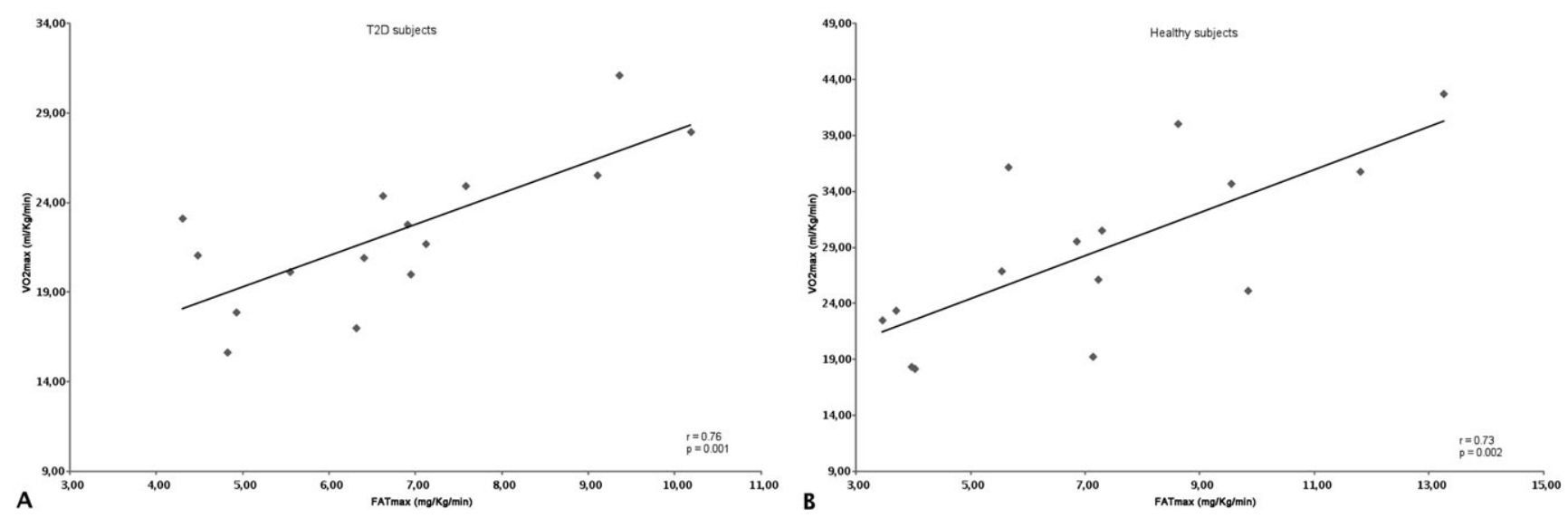

Figure 2. Correlations between $\mathrm{FAT}_{\max }$ and $\mathrm{VO}_{2 \max }$ in type 2 diabetes (A) and healthy (B) subjects. 
sity. Moreover, the positive linear correlation between $\mathrm{FAT}_{\max }$ and both $\mathrm{VO}_{2}$ and $\mathrm{VO}_{2 \text { max }}$ suggests that even in T2D patients the muscle oxidative capacity might increase in response to aerobic training, and this could contribute to reduction of body fat mass.

\section{References}

1. Romijn JA, Coyle EF, Sidossis LS, et al. Regulation of endogenous fat and carbohydrate metabolism in relation to exercise intensity and duration. Am J Physiol-Endoc M 1993;265:E380-91.

2. Martin WH III, Klein S. Use of endogenous carbohydrate and fat as fuels during exercise. Proc Nutr Soc 1998;57:49-54.
3. Cataldo A, Russo G, Zangla D, et al. Determination of maximal fat oxidation for prescribing exercise in healthy sedentary subjects. Proc. of XXXII World Congress of Sport Medicine, Rome, 2012.

4. Regensteiner JG, Sippel J, McFarling ET, et al. Effects of noninsulin dependent diabetes on oxygen consumption during treadmill exercise. Med Sci Sport Exer 1995;27:875-81.

5. Vranic M. Physiology and biochemistry of exercise in insulin-resistant states. Proc. of 60th Sc. Sess. of the Am. Diab. Ass.; San Antonio, Texas; 2000.

6. Achten J, Jeukendrup A. Optimizing fat oxydation through exercise and diet. Nutrition 2004;20:716-27.

7. Borghouts LB, Wagenmakers AJM, Goyens PLL, Keizer HA. Substrate utilization in non-obese Type II diabetic patients at rest and during exercise. Clin Sci 2002;103:559-66. 